\title{
Presentación al Dossier Geografía - Técnica - Geografías
}

Hortensia Castro, Verónica Hollman y Diego Ríos ${ }^{1}$

La imagen de la portada (Stillness in Motion - Cloud Cities, 2016), obra del artista argentino Tomás Saraceno, nos permite reflexionar sobre varios asuntos implicados en la relación técnica-espacio, objeto de este Dossier. En primer lugar, nos sugiere cuán enredadas se encuentran nuestras vidas en relación con objetos y procesos técnicos; por ejemplo, cómo nuestras experiencias espaciales están cada vez más moldeadas por las tecnologías de la información y la comunicación así como por las de seguridad y control. En segundo lugar, esboza otras cuestiones, también claves en los estudios geográficos, como la mediación técnica de lo visible y lo invisible (ya sean sujetos, objetos o lugares) y nos invita a indagar sus posibles derivaciones, por ejemplo en términos de imaginarios geográficos o derechos territoriales. Asimismo, insinúa la reconfiguración de lo próximo y de lo lejano a través de ciertas innovaciones tecnológicas y, con ello, la definición de sujetos y espacios integrados o segregados; en otros términos, nos remite a un extenso debate acerca de la técnica como instrumento de liberación o de dominio y clausura.

Si bien en la historia del pensamiento geográfico la técnica ha constituido una categoría a la que han apelado distintas tradiciones para abordar y comprender la configuración del espacio, en la actualidad el fenómeno técnico ha cobrado una relevancia tal que amerita la revisión y el debate epistemológico, teórico- metodológico, empírico y político de sus alcances, implicancias y desafíos. En ese sentido, este Dossier propone una serie de tematizaciones y perspectivas para comprender los modos en que el fenómeno técnico participa de la producción y comprensión de las geografías (del presente y del pasado), así como sus implicancias y tensiones asociadas. Y tal como sugiere su título (Geografía - Técnica - Geografías), busca propiciar una mirada disciplinar acerca de la relación técnica-espacio; entre otros aspectos, interesa reflexionar en torno a la trama de planteos teóricos y metodológicos potentes para captar las novedades y continuidades que impone el fenómeno técnico y, para ello, los posibles diálogos entre la tradición y la renovación disciplinar.

Los artículos que componen este Dossier expresan sólidas y auspiciosas contribuciones a la temática. El primer texto "Espacio geográfico y fenómeno técnico: cuestiones de método", de María Laura Silveira, busca ir más allá de las técnicas particulares para abordar el fenómeno técnico (sus modos de uso y la política subyacente en sus

1 Agradecemos a Santiago Urrutia Reveco por su colaboración en la revisión de los artículos que componen este Dossier. 
combinaciones y localizaciones), enfatizar su condición de tiempo empirizado y, desde allí, comprender la naturaleza sistémica de las técnicas de la globalización. El artículo de Villy Creuz "Una mirada sobre la técnica en los estudios geográficos" se propone indagar y reflexionar sobre el tratamiento de la cuestión de la técnica en la Filosofía y la Geografía, con especial atención a su distinción como objeto y principio de acción. El artículo de Tilo Felgenhauer "La renovada importancia de los conceptos geográficos tradicionales en la construcción digital del espacio y del lugar" identifica y propone un modelo de aproximación a una de las paradojas contemporáneas: la coexistencia/ yuxtaposición de interacciones cotidianas de los sujetos con los dispositivos digitales en una micro-escala (por ejemplo a través de aplicaciones sencillas y accesibles en las pantallas de los smart phones), con prácticas que necesariamente requieren el dominio de una representación espacial en términos algorítmicos y numéricos; y toponimias que vuelven a inscribir identidades locales, regionales y/o nacionales. Carla Lois y Malena Mazzitelli Mastricchio, en su texto "Del ojo a la mirada: debates sobre el sentido de la vista y las técnicas de observación y registro en la ciencia moderna”, asumen a las técnicas de observación y sus instrumentos como parte intrínseca a los modos de producir conocimiento, analizan algunas transformaciones en esas técnicas y sus derivaciones en cuanto a lo visible y las habilidades requeridas, e indagan sobre el lugar de la técnica en la problematización del acto de ver y la construcción cultural de la mirada. El Dossier cierra con un artículo de Rogério Haesbaert, "Muros como tecnologías y dispositivos territoriales de control”, en el que discute a los muros como tecnología arcaica para interpretarlos, en cambio, como expresión de una nueva interacción entre diferentes modalidades de control (no sólo de televigilancia sino también de amurallamiento) que marcan nuestro tiempo. A través del análisis de la construcción de distintas modalidades de murallas, el texto también problematiza la producción del territorio y, especialmente, la configuración de territorios-muro como dispositivo de poder y, al mismo tiempo, de dominación técnico-material y de apropiación simbólica.

Esos artículos, considerados en su conjunto, también permiten reconocer una serie de ejes para problematizar la relación técnica-espacio, que a su vez habilitan nuevas lecturas de los textos.

Uno de esos ejes refiere a la relación técnica, espacio y tiempo. Como se señala al inicio, el objeto temático de este Dossier es la relación técnica-espacio, más precisamente la reflexión acerca del modo en que la creación de técnicas transforma nuestros espacios y, por ende, a nosotros mismos (una derivación de esa relación, de gran vigencia en el debate latinoamericano actual, son las controversias técnicas en cuanto a la difusión de organismos genéticamente modificados y los efectos contaminantes de ciertas sustancias químicas utilizadas en diversos usos productivos). Ahora, como bien señalan varios textos de este número, esa relación técnica-espacio necesita ser historizada, ser evaluada en términos de los tiempos que participan de ella y lo que generan; por ejemplo, como señala Santos (2000), ¿̇a qué percepción del tiempo conduce cada nueva técnica?, ¿̇a qué forma de uso del tiempo obliga? Estas cuestiones son claves en el contexto de globalización neoliberal, por ejemplo en cuanto a la coexistencia de diversas divisiones sociales y territoriales del trabajo o la valorización diferencial de elementos naturales e histórico-culturales como recursos estratégicos.

Otro de esos ejes remite a la condición material e inmaterial de la técnica, un par indisociable que no siempre ha sido explorado de manera combinada e imbricada. De 
hecho, Villy Creuz nos advierte en su texto que la dimensión inmaterial de la técnica (es decir, las formas de pensar, planear, normar y actuar técnicamente) ha sido comparativamente menos incorporada a las reflexiones en Geografía que la dimensión material de la técnica (es decir, en tanto objetos y herramientas). Incluso Rogério Haesbaert y Carla Lois-Malena Mazzitelli Mastricchio nos llevan a reflexionar sobre la necesidad de considerar tanto las formas de dominación material, instituidas a través de los objetos técnicos y las habilidades requeridas para ello, como también las estrategias de apropiación simbólica vehiculizadas.

Un tercer eje analítico, transversal a los artículos y asociado a la reflexión anterior, remite más explícitamente a la relación técnica y poder. Más precisamente, nos lleva a la necesidad de reconocer los diferentes regímenes de visibilidad que participan de los procesos de producción territorial (como los muros y los instrumentos de observación, para señalar dos tipos de dispositivos analizados por los textos de este Dossier), prestar atención a las estrategias que buscan instalar un velo a esa relación (en términos de las ilusiones de opacidad y transparencia) y, de esta manera, contribuir al desarrollo de discusiones argumentadas sobre la neutralidad de la técnica.

Por último, sin cerrar aquí la discusión, la fotografía de la instalación de Tomás Saraceno delinea otro de los ejes que atraviesa la totalidad de artículos de este Dossier. La arquitectura de la obra -redes en redes-y los elementos que la componen -particularmente los espejos y las formas de las estructuras- intervienen para que las personas que recorren la instalación asuman una doble condición: ellas están inmersas en alguna de las estructuras que integran la instalación y, simultáneamente, están en y desde los márgenes como condición para recorrerla. De modo análogo, los autores de este Dossier examinan la relación técnica-geografía valiéndose de categorías internas y externas de la disciplina. Tal vez, aquí resida otra de las contribuciones de este Dossier: los autores vuelven a mirar el espejo de la disciplina e identificar las potencias que ella nos ofrece y, a la vez, deciden caminar con intrepidez por sus márgenes para habilitar otros interrogantes y diálogos que la propia temática exige.

Este Dossier ha sido organizado desde el Grupo Cultura Naturaleza Territorio, ${ }^{2}$ un ámbito de reflexión y debate en torno al papel que juegan las ideas sobre la naturaleza y la cultura en los procesos de producción territorial, así como las implicancias de las transformaciones territoriales en la propia producción de ideas sobre naturaleza y cultura. Desde esos intereses y preocupaciones, consideramos que los artículos que componen este número contribuyen notablemente a profundizar nuestra comprensión del contenido crecientemente técnico que está adquiriendo el espacio geográfico y las conexiones materiales y simbólicas entre cultura/s y naturaleza/s que participan de él. 